\title{
THE PREVALENCE OF EXCESSIVE DAYTIME SLEEPINESS AMONG ACADEMIC PHYSICIANS AND ITS IMPACT ON THE QUALITY OF LIFE AND OCCUPATIONAL PERFORMANCE
}

\section{ACLAN OZDER ${ }^{1}$ and HASAN HUSEYIN EKER ${ }^{2}$}

\author{
Bezmialem Vakif University, Istanbul, Turkey \\ Faculty of Medicine \\ ${ }^{1}$ Department of Family Medicine \\ ${ }^{2}$ Department of Public Health
}

\begin{abstract}
Objectives: Sleep disorders can affect health and occupational performance of physicians as well as outcomes in patients. The purpose of this study was to assess the prevalence of excessive daytime sleepiness (EDS) measured by the Epworth Sleepiness Scale (ESS) among academic physicians at a tertiary academic medical center in an urban area in the northwest region of Turkey, and to establish a relationship between the self-perceived sleepiness and the quality of life using the EuroQol-5 dimensions (EQ-5D). Material and Methods: A questionnaire prepared by the researchers after scanning the literature on the subject was e-mailed to the academic physicians of a tertiary academic medical center in Istanbul. The ESS and the EQ-5D were also included in the survey. The e-mail database of the institution directory was used to compile a list of active academic physicians who practiced clinical medicine. Paired and independent $t$ tests were used for the data analysis at a significance level of $\mathrm{p}<0.05$. Results: Three hundred and ninety six academic physicians were e-mailed and a total of 252 subjects replied resulting in a $63.6 \%$ response rate. There were $84(33.3 \%)$ female and $168(66.7 \%)$ male academic physicians participating in the study. One hundred and eight out of $252(42.8 \%)$ academic physicians were taking night calls $(\mathrm{p}<0.001)$. Ninety study subjects $(35.7 \%)$ felt they had enough sleep and $84(33.3 \%)$ reported napping daily $(\mathrm{p}<0.001)$. In our sample, $28.6 \%(\mathrm{~N}=72)$ of the physicians felt sleepy during the day (ESS score $>10)(\mathrm{p}<0.001)$. In the case of the EQ-5D index and visual analogue scale of the EQ-5D questionnaire (EQ-5D VAS), the status of sleepiness of academic physicians was associated with a poorer quality of life $(\mathrm{p}<0.001)$. Conclusions: More than a $1 / 4$ of the academic physicians suffered from sleepiness. There was an association between the poor quality of life and daytime sleepiness. There was also a positive relationship between habitual napping and being sleepy during the day.
\end{abstract}

Key words:

Academician physician, Epworth, EQ-5D, Habitual napping, Sleepiness, Sleep disorders

\section{INTRODUCTION}

Excessive daytime sleepiness (EDS) can be defined as a difficulty in maintaining a desired level of wakefulness, often accompanied by the symptoms such as psychomotor slowing and closing eyelids for a longer time than for the purpose of blinking [1,2]. In addition to interfering with daily functioning and affecting behaviors, and job performance, excessive daytime sleepiness is more likely to cause malpractices

Received: June 26, 2014. Accepted: November 26, 2014.

Corresponding author: A. Ozder, Bezmialem Vakif University, Faculty of Medicine, Department of Family Medicine, Adnan Menderes Boulevard 34093 Fatih, Istanbul, Turkey (e-mail: aclan.ozder@aol.com). 
related to human error [3]. As overwork and sleep deprivation in physicians can directly result in medical incidents, it is essential to investigate the actual situation concerning this issue and take appropriate measures towards ensuring medical safety [4]. Daytime sleepiness may be directly associated with lower academic performance [5].

It has been reported that long working hours and sleep deprivation affect both mental state and physical function, causing excessive daytime sleepiness and a decline in cognitive functions [6-11]. Excessive daytime sleepiness (EDS) is a major clinical and public health concern affecting 10-25\% of the general population, mainly adolescents, older people and shift workers [12]. Shift work is common in medical professions and is necessary for 24-h hospital coverage. Shift work poses difficulties not only because of the loss of actual sleep hours, but also because it can affect other factors related to the lifestyle, such as food intake, physical activity level, and, therefore, metabolic patterns [13].

The causes of EDS are multifactorial, with possible risk factors previously identified as intrinsic sleep disorders, such as narcolepsy, obstructive sleep apnea; circadian rhythm disorders such as shift-work disorder; extrinsic sleep disorders such as poor sleep hygiene and insufficient sleep [14]; and other contributory lifestyle and health factors [15]. In a previous study, it has been demonstrated that after-hours on-call has a generally negative impact on paediatricians' spouses and families [16]. Caffeine is one of the most widely consumed psychoactive substances and it has profound effects on sleep and wake functions. Laboratory studies have documented its sleep-disruptive effects. It clearly enhances alertness and performance at work with explicit sleep deprivation, restriction or circadian sleep schedule reversals [17]. Majority of the previous studies about EDS among physicians have been performed mainly among medical residents, and only rarely in academics [18-20]. However, since the problem of daily performance and sleep among physicians is not limited to medical residents, it should be addressed by investigating also the population of academic physicians.
Health related quality of life (HRQoL) assessment is an increasingly important aspect of the current medical practice. To the best of our knowledge, no publications concerning the relationship between the self-perceived sleepiness and the quality of life of academic physicians are available, including no publications concerning sleepiness in Turkish academics.

Therefore, the purpose of this study was to assess the prevalence of excessive daytime sleepiness (EDS) measured by the Epworth Sleepiness Scale (ESS) among academic physicians at a tertiary academic medical center in an urban area in the northwest region of Turkey, and to establish the relationship between the self-perceived sleepiness and the quality of life using the EuroQol-5 dimensions (EQ-5D).

\section{MATERIAL AND METHODS}

A questionnaire prepared by the researchers investigating socio-demographic, sleep and job characteristics was e-mailed to attending academic physicians of a tertiary academic medical center in Istanbul. The Epworth Sleepiness Scale (ESS) and the EuroQol-5 dimensions (EQ-5D) were also included in the survey. The e-mail database of the institution's directory was used to compile a list of active academic physicians who practiced clinical medicine. Those involved entirely in basic science departments were excluded from the study. Two additional reminder e-mails in about 2-week intervals were sent to increase the response. The data were collected from April 2014 to May 2014 in an anonymous manner and participation in the study was voluntary. Personal identity numbers were requested prior to filling in the survey to prevent the study participants from responding more than once. Hence, the questionnaire submission system did not let the same person to respond more than 1 time.

Bezmialem Vakif University Hospital is a tertiary care hospital. It is one of the largest hospitals in Istanbul with 396 academic physicians. The participants filled in the questionnaire online and completed information concerning 
socio-demographic, general and sleep characteristics. Socio-demographic data included: age (in years), gender (male, female), marital status (married, unmarried, divorced), weight (in $\mathrm{kg}$ ) and height (in $\mathrm{cm}$ ) expressed by the respondents and information if they had children (the number of children in the household). General characteristics included: an academic physicians' seniority (in years); working hours (per week); caffeine intake (the number of drinks); tobacco (frequency). Sleep characteristics were described by obtaining information on: the average sleep hours per night ( $<6 \mathrm{~h}, 6-7 \mathrm{~h}, 7-8 \mathrm{~h},>8 \mathrm{~h}$ ), taking night calls (yes, no), regular sleep aid use such as sleeping pills taken orally (yes, no) and the self-perceived sleepiness.

Academic physicians were asked to complete 2 instruments: the Epworth Sleepiness Scale (ESS), which assessed the self-perceived sleepiness, and the EQ-5D scale, which assessed the general quality of life based on experiences over the previous month.

A validated Turkish version of the ESS was used to assess sleepiness [21]. The ESS is a standardized validated questionnaire that assesses the likelihood that the subject will fall asleep during certain activities. The ESS is the most widely used subjective scale for assessing daytime sleepiness because it is able to distinguish between people with and without sleepiness.

The ESS consists of 8 questions that describe everyday situations that can induce sleepiness. Each question is graded from 0 ("not at all likely to fall asleep") to 3 ("very likely to fall asleep"). The ESS ranges from 0 to 24, and can be used to categorize respondents as normal (ESS $\leq 10)$ and as suffering from excessive daytime sleepiness (ESS > 10) [22]. The ESS is a simple, self-administered questionnaire, which is shown to provide a measurement of the subject's general level of daytime sleepiness. Cronbach's $\alpha$ coefficients for the Turkish version of the ESS indicated excellent internal consistency. The internal consistency level (Chronbach's $\alpha$ coefficients) of the Turkish version of the ESS was 0.87 .
The 1st part of the EQ-5D contains a description of the health state in 5 dimensions or items: Mobility, Selfcare, Usual activities, Pain/Discomfort and Anxiety/Depression. Levels of severity for each item might be expressed as 1 ("No problems"), 2 ("Some problems") and 3 ("Unable to do / Extreme problems"). For each item, a respondent must indicate the level of severity that best describes his/ her personal health state at the time of giving the answers. A subject's global health state is finally defined as a combination of the level of problems described for each of the $5 \mathrm{di}$ mensions contained in the EQ-5D. Therefore, it classifies a respondent's health status into 1 of $243\left(3^{5}=243\right)$ health states. Each health state can be assigned a weighted utility score based on different scoring systems.

The rule for unweighted scoring was based solely on the answers provided by the subjects to the descriptive system. The values range from -0.59 (the lowest level on each dimension) to 1 (the highest level on each dimension). Negative values indicate unfavorable health states like living loss of consciousness or being bedridden. The 2 nd part of the EQ-5D questionnaire is a visual analogue scale (EQ-VAS). The EQ-VAS is a vertical, graduated (0100 points) $20 \mathrm{~cm}$ "thermometer," with 100 representing "the best imaginable health state" and 0 representing "the worst imaginable health state." Each respondent rated his/ her health on the day of the survey using both the self-classifier system and the VAS. The Turkish version of the EQ$5 \mathrm{D}$ is a valid and reliable generic HRQoL instrument [23].

\section{ETHICS}

Ethical approval was obtained from the institutional review board prior to the commencement of the study.

\section{STATISTICS}

The data obtained in the study were analyzed using the Statistical Package for the Social Sciences (SPSS) for Windows version 16 (SPSS, Inc., Chicago, IL, USA). Continuous variables are expressed as means \pm standard 
deviation $(\mathrm{M} \pm \mathrm{SD})$ and compared using the Spearman's correlation and $\mathrm{Chi}^{2}$ tests. For categorical variables, the percentages of patients in each category were calculated. The T test was used to compare independent groups. $\mathrm{P}$ value smaller than $0.05(\mathrm{p}<0.05)$ was considered as statistically significant.

\section{RESULTS}

Three hundred and ninety six academic physicians were e-mailed and a total of 252 subjects responded resulting in a $63.6 \%$ response rate. The mean age of the study population was $39.90 \pm 9.99$ years $(\mathrm{M} \pm \mathrm{SD})$. When compared, the age of the males and females in the group was significantly different $(\mathrm{p}<0.05)$. The mean seniority of the overall group was $14.98 \pm 10.22$ years. The mean body mass index (BMI) in the entire group was $26.69 \pm 3.08$.

One hundred and eight out of $252(42.8 \%)$ academics were taking night calls. However, $60(83.3 \%)$ academics among the ESS score $\geq 10$ group were taking night calls and a statistically significant difference was found when compared with the ESS score $<10$ group $(\mathrm{p}<0.05)$. Only a small number of the academics ( $\mathrm{N}=18,7.1 \%)$ said that they used sleep aids regularly in a form of alprazolam or benzodiazepine tablets taken orally. Ninety subjects (35.7\%) felt they had enough sleep and $84(33.3 \%)$ reported napping daily ( $p<0.05)$. In our sample, $28.6 \%(\mathrm{~N}=72)$ of the study subjects were sleepy during the day (ESS score $>10$ ) and the mean ESS score was 8.38 \pm 5.41 . Demographic and substance use results are shown in Table 1.

Concerning some other characteristics; the status of sleepiness was associated with: taking night calls (no sleepiness - 48 subjects (44.4\%), with sleepiness - 60 subjects $(55.6 \%), \mathrm{p}<0.05$ ); habitual napping (no sleepiness 30 subjects (35.7\%), with sleepiness - 54 subjects (64.3\%), $\mathrm{p}<0.05)$. The results concerning variables that affected the quality of life (EQ-5D index) are summarized in Table 2. With regard to the EQ-5D index, the status of sleepiness of academic physicians was associated with
Table 1. Demographic and substance use results

\begin{tabular}{lc}
\hline \multicolumn{1}{c}{ Variable } & $\begin{array}{c}\text { Respondents } \\
(\mathrm{N}=252)\end{array}$ \\
\hline Age [years] $(\mathrm{M} \pm \mathrm{SD})$ & $39.90 \pm 9.99$ \\
Body mass index $(\mathrm{M} \pm \mathrm{SD})$ & $26.69 \pm 3.08$ \\
Gender [n (\%)] & \\
female & $84(33.3)$ \\
male & $168(66.7)$ \\
Marital status: married [n (\%)] & $186(73.8)$ \\
Work [n (\%)] & \\
$<$ 40 h/week & $24(9.5)$ \\
40-60 h/week & $180(71.4)$ \\
$>$ 60 h/week & $48(19.0)$ \\
Seniority [years] $(\mathrm{M} \pm \mathrm{SD})$ & $14.98 \pm 10.22$ \\
Average sleep [n $(\%)]$ & \\
$<$ 6 h/night & $72(28.6)$ \\
6-7 h/night & $114(45.2)$ \\
7-8 h/night & $60(23.8)$ \\
$>8 \mathrm{~h} /$ night & $6(2.4)$ \\
Taking night calls [n $(\%)]$ & $108(42.8)$ \\
Children in the household [n] $(\mathrm{M} \pm \mathrm{SD})$ & $1.24 \pm 1.32$ \\
Regular sleep aid use [n $(\%)]$ & $18(7.1)$ \\
Caffeinated drinks [n $(\%)]$ & \\
$<$ < 1 cups/day & $78(30.9)$ \\
1-2 cups/day & $132(52.4)$ \\
3-4 cups/day & $30(11.9)$ \\
$>$ 4 cups/day & $12(4.8)$ \\
\hline
\end{tabular}

M - mean; SD - standard deviation.

a poorer quality of life $(0.87 \pm 0.15$ in ESS $\leq 10$ group and $0.54 \pm 0.19$ in ESS $>10$ group, $p<0.001$ ) (Figure 1). In terms of the EQ-5D VAS, the status of sleepiness of academic physicians was associated with a poorer quality of life (90.90 \pm 6.36 in ESS $\leq 10$ group and 51.92 \pm 13.05 ESS $>10$ group, $p<0.001$ ) (Figure 2). Sleep characteristics in all the academic physicians depending on the status of sleepiness are presented in Table 3.

Among the study group, smoking prevalence was found statistically higher in males $(\mathrm{N}=60,35.7 \%)$ when compared to the females $(\mathrm{N}=18,21.4 \%)(\mathrm{p}<0.001)$. 
Table 2. The EuroQol-5 dimensions (EQ-5D) scores among the study subjects

\begin{tabular}{llcc}
\hline \multirow{2}{*}{ Variable } & \multicolumn{3}{c}{$\begin{array}{c}\text { Answers } \\
{[\mathrm{n}(\%)]}\end{array}$} \\
\cline { 2 - 4 } & no problem & some problem & extreme problem \\
\hline Mobility & $222(88.1)$ & $30(11.9)$ & $0(0.0)$ \\
Self-care & $252(100.0)$ & $0(0.0)$ & $0(0.0)$ \\
Usual activities & $234(92.9)$ & $18(7.1)$ & $0(0.0)$ \\
Pain/Discomfort & $174(69.0)$ & $78(31.0)$ & $0(0.0)$ \\
Anxiety/Depression & $120(47.6)$ & $114(45.2)$ & $18(7.1)$ \\
\hline
\end{tabular}

Table 3. Some features of the study group according to daytime sleepiness

\begin{tabular}{|c|c|c|c|c|}
\hline \multirow[b]{2}{*}{ Variable } & \multicolumn{2}{|c|}{ Respondents } & \multirow[b]{2}{*}{$\mathrm{p}$} & \multirow[b]{2}{*}{$\mathrm{Chi}^{2}$} \\
\hline & $\begin{array}{c}\text { ESS score < } 10 \\
(\mathrm{~N}=180)\end{array}$ & $\begin{array}{c}\text { ESS score } \geq 10 \\
(N=72)\end{array}$ & & \\
\hline Age [years] $(\mathrm{M} \pm \mathrm{SD})$ & $39.67 \pm 9.30$ & $40.50 \pm 11.29$ & 0.547 & 0.603 \\
\hline Gender $[\mathrm{n}(\%)]$ & & & 0.076 & 3.15 \\
\hline female & $66(36.7)$ & $18(25.0)$ & & \\
\hline male & $114(63.3)$ & $54(75.0)$ & & \\
\hline Marital status [n (\%)] & & & $<0.05$ & 6.93 \\
\hline single & $36(20.0)$ & $24(33.3)$ & & \\
\hline married & $138(76.7)$ & $48(66.7)$ & & \\
\hline widow/divorced & $6(3.3)$ & $0(0.0)$ & & \\
\hline Tobacco usage [n (\%)] & & & $<0.01$ & 14.53 \\
\hline no & $132(73.3)$ & $42(58.3)$ & & \\
\hline rarely & $6(3.3)$ & $12(16.7)$ & & \\
\hline every day & $42(23.3)$ & $18(25.0)$ & & \\
\hline Caffeine drinks [n (\%)] & & & $<0.001$ & 20.98 \\
\hline$<1$ cup/day & $60(33.3)$ & $18(25.0)$ & & \\
\hline $1-2$ cups/day & $84(46.7)$ & $48(66.7)$ & & \\
\hline 3-4 cups/day & $30(16.7)$ & $0(0.0)$ & & \\
\hline$>4$ cups/day & $6(3.3)$ & $6(8.3)$ & & \\
\hline Work [n (\%)] & & & $<0.001$ & 28.07 \\
\hline$<40$ h/week & $6(3.35)$ & $18(25.0)$ & & \\
\hline 40-60 h/week & $138(76.7)$ & $42(58.3)$ & & \\
\hline$>60 \mathrm{~h} /$ week & $36(20.0)$ & $12(16.7)$ & & \\
\hline Average sleep [n (\%)] & & & $<0.05$ & 8.83 \\
\hline$<6 \mathrm{~h} /$ night & $54(30.0)$ & $18(25.0)$ & & \\
\hline $6-7 \mathrm{~h} /$ night & $72(40.0)$ & $42(58.3)$ & & \\
\hline $7-8 \mathrm{~h} /$ night & $48(26.7)$ & $12(16.7)$ & & \\
\hline$>8 \mathrm{~h} /$ night & $6(3.3)$ & $0(0.0)$ & & \\
\hline
\end{tabular}


Table 3. Some features of the study group according to daytime sleepiness - cont.

\begin{tabular}{|c|c|c|c|c|}
\hline \multirow[b]{2}{*}{ Variable } & \multicolumn{2}{|c|}{ Respondents } & \multirow[b]{2}{*}{$\mathrm{p}$} & \multirow[b]{2}{*}{$\mathrm{Chi}^{2}$} \\
\hline & $\begin{array}{c}\text { ESS score }<10 \\
\quad(N=180)\end{array}$ & $\begin{array}{c}\text { ESS score } \geq 10 \\
(\mathrm{~N}=72)\end{array}$ & & \\
\hline Habitual napping [n (\%)] & & & $<0.001$ & 78.75 \\
\hline yes & $30(16.7)$ & $54(75.0)$ & & \\
\hline no & $150(83.3)$ & $18(25.0)$ & & \\
\hline Taking night calls $[\mathrm{n}(\%)]$ & & & $<0.001$ & 67.43 \\
\hline yes & $48(26.7)$ & $60(83.3)$ & & \\
\hline no & $132(73.3)$ & $12(16.7)$ & & \\
\hline \multicolumn{5}{|l|}{ General quality of life $(\mathrm{M} \pm \mathrm{SD})$} \\
\hline EQ-5D index & $0.87 \pm 0.15$ & $0.54 \pm 0.19$ & $<0.001$ & 154.46 \\
\hline EQ-VAS & $90.90 \pm 6.36$ & $51.92 \pm 13.05$ & $<0.001$ & 252.00 \\
\hline $\begin{array}{l}\text { Subjective sense of not getting enough } \\
\text { sleep }[\mathrm{n}(\%)]\end{array}$ & & & $<0.001$ & 15.92 \\
\hline yes & $78(43.3)$ & $12(16.7)$ & & \\
\hline no & $102(56.7)$ & $60(83.3)$ & & \\
\hline
\end{tabular}

EES - Epworth Sleepiness Scale; EQ-5D - EuroQol-5 dimensions; EQ-VAS - visual analogue scale of the EQ questionnaire; Chi ${ }^{2}$ - Chi-square test. Other abbreviations as in Table 1.

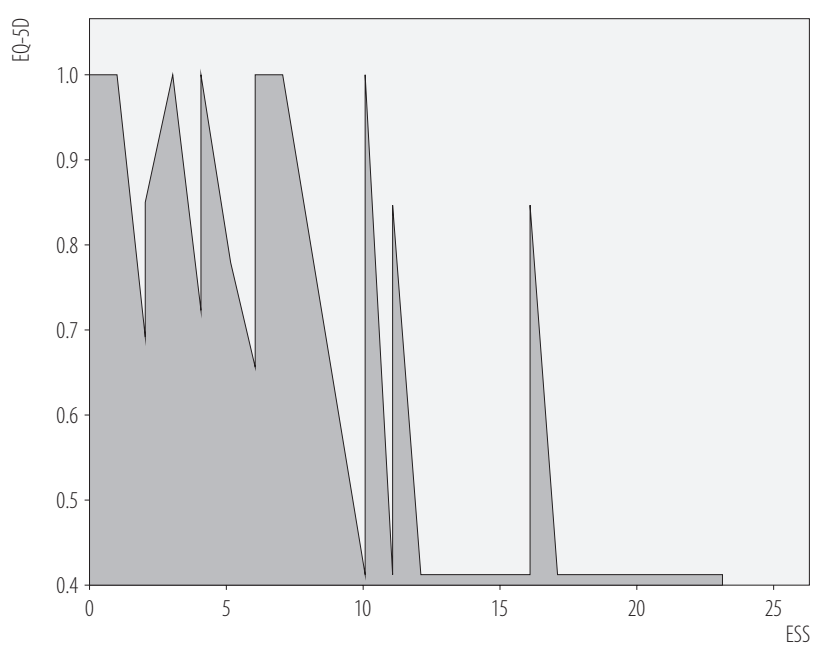

Fig. 1. Comparison of the Epworth Sleepiness Scale scores and the EuroQol-5 dimensions index

The mean daily sleeping hours of the males amounted to $5.82 \pm 0.71$. When compared, daily sleeping hours of the males and females in the group were statistically different $(p<0.001)$. Gender differences among the study group are presented in Table 4.

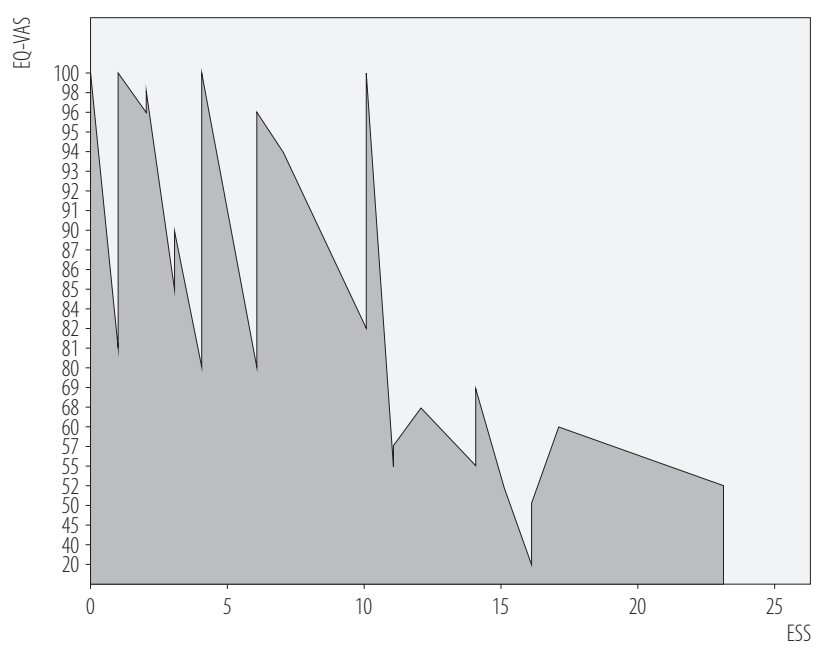

Fig. 2. Comparison of the Epworth Sleepiness Scale scores and the visual analogue scale of the EuroQol questionnaire

Correlation of some group characteristics with the ESS score showed that the subjects with EDS were having habitual naps and were taking night calls statistically more frequently when compared to the subjects without EDS ( $p<0.001)$ (Table 5). 
Table 4. Gender differences among the study group

\begin{tabular}{|c|c|c|c|}
\hline \multirow[b]{2}{*}{ Variable } & \multicolumn{2}{|c|}{ Respondents } & \multirow[b]{2}{*}{$\mathrm{p}$} \\
\hline & $\begin{array}{c}\text { female } \\
(\mathrm{N}=84)\end{array}$ & $\begin{array}{c}\text { male } \\
(\mathrm{N}=168)\end{array}$ & \\
\hline 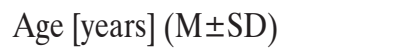 & $33.50 \pm 8.24$ & $43.11 \pm 9.08$ & $<0.001$ \\
\hline ESS score $\geq 10[\mathrm{n}(\%)]$ & $18(21.4)$ & $54(32.1)$ & 0.0790 \\
\hline Smoking prevalence $[\mathrm{n}(\%)]$ & $18(21.4)$ & $60(35.7)$ & $<0.001$ \\
\hline Working [h/week] $(\mathrm{M} \pm \mathrm{SD})$ & $50.00 \pm 5.37$ & $51.43 \pm 5.16$ & $<0.050$ \\
\hline Sleeping [h/day] $(\mathrm{M} \pm \mathrm{SD})$ & $6.43 \pm 0.98$ & $5.82 \pm 0.71$ & $<0.001$ \\
\hline Naps $[\mathrm{n}(\%)]$ & $12(14.2)$ & $72(42.8)$ & $<0.001$ \\
\hline Taking night calls [n (\%)] & $24(28.6)$ & $84(50.0)$ & $<0.050$ \\
\hline Night shift [n (\%)] & $24(40.0)$ & $36(60.0)$ & 0.214 \\
\hline EQ-5D index $(M \pm S D)$ & $0.77 \pm 0.22$ & $0.77 \pm 0.21$ & 0.941 \\
\hline EQ-VAS $(\mathrm{M} \pm \mathrm{SD})$ & $82.64 \pm 19.49$ & $78.32 \pm 19.55$ & 0.099 \\
\hline
\end{tabular}

Abbreviations as in Table 1 and 3.

Table 5. Correlation of some group characteristics with the Epworth Sleepiness Scale (ESS) score

\begin{tabular}{lccc}
\hline \multicolumn{1}{c}{ Variable } & $\begin{array}{c}\text { ESS score } \\
(\mathrm{M} \pm \mathrm{SD})\end{array}$ & $\mathrm{p}$ & $\mathrm{t}$ \\
\hline $\begin{array}{l}\text { Gender } \\
\text { female }\end{array}$ & $8.00 \pm 5.47$ & 0.426 & \\
$\quad$ male & $8.57 \pm 5.31$ & & \\
Habitual napping & & $<0.001$ & \\
$\quad$ yes & $12.78 \pm 4.35$ & & \\
no & $6.17 \pm 4.37$ & & \\
Taking night calls & & $<.40$ \\
$\quad$ yes & $11.00 \pm 5.60$ & & \\
no & $6.41 \pm 4.22$ & & \\
\hline
\end{tabular}

Abbreviations as in Table 1 and 3.

Table 6. Correlation of the EuroQol-5 dimensions (EQ-5D) variables with the Epworth Sleepiness Scale (ESS)

\begin{tabular}{|c|c|c|}
\hline \multirow{2}{*}{ Variable } & \multicolumn{2}{|c|}{ EQ-5D/ESS correlation } \\
\hline & $\mathrm{p}$ & Spearman's rho \\
\hline Mobility & 0.208 & 0.080 \\
\hline Self-care & 0.384 & -0.055 \\
\hline Usual activities & 0.466 & 0.046 \\
\hline Pain/Discomfort & 0.542 & 0.039 \\
\hline Anxiety/Depression & $<0.001$ & 0.517 \\
\hline
\end{tabular}

Abbreviations as in Table 3. 
The correlation of the EQ-5D variables with the ESS is presented in Table 6. Anxiety/depression subscore of the EQ-5D was found to be higher among the participants with $\operatorname{EDS}(\mathrm{p}<0.001)$.

\section{DISCUSSION}

To the best of our knowledge, this study is the first one that has established the relationship between the self-perceived sleepiness using the valid Turkish version of the ESS and the general quality of life using the valid Turkish version of the EQ-5D among academic physicians from Turkey. In our sample, 28.6\% of the study subjects $(\mathrm{N}=72)$ were sleepy during the day (ESS score $>10$ ) and the mean ESS score was $8.38 \pm 5.41$. This prevalence was similar to the results of some studies with the rates ranging 6.3-22.6\% among the general population or non-shift workers [2427], and 5.9-44.8\% in shift workers [28,29]. In a previous study performed among both academic and private practice physicians, the mean ESS of 7.8 and the prevalence of EDS of $23 \%$ have been reported, which is slightly lower than in the case of our population [30]. Excessive daytime sleepiness among academic physicians correlated positively and significantly with habitual napping, with the subjective sense of not getting enough sleep and with actual hours of work per week as well as with the number of hours slept per night. This is slightly different from the results from the 2 previous studies [30,31]. In those studies, it has been found that EDS negatively correlated with hours slept at night and positively with habitual napping, but not with hours of work per week. This means those with greater EDS slept on average fewer hours per night. The difference in our study could be due to the ability of the physicians to handle their own symptoms despite longer hours of work per week. This may also suggest that habitual napping may be as good an indicator of EDS as of ESS in our population.
Habitual napping may explain why there was no correlation between the subjective sleepiness and the hours of sleep per night. The subjects in our sample who slept fewer hours per night may have been napping during the day to restore their sleep deprivation; therefore, although the number of hours at night was smaller, this did not correlate with EDS. A short nap has been associated with improved performance, alertness and a reduced risk of an accident [32]. It could also be that physicians in our sample were more forbearing to sleep deprivation and, therefore, did not feel the influence of it in a form of excessive daytime sleepiness. A nap is typically a masculine way of coping with sleepiness during the day. We think that the female participants responded to sleep deprivation and tried to overcome sleepiness by increasing daily sleeping hours $(6.43 \pm 0.98 \mathrm{~h}$ in females and $5.82 \pm 0.71 \mathrm{~h}$ in males) $(p<0.001)$. However, we do not know if they practiced habitual napping because their quality of life was decreased or because they had excessive daytime sleepiness. This issue is one of the limitations of the study. We found a significant relationship between taking night calls and EDS $(p<0.05)$. This might be concluded from the sleep interruptions caused by night calls during sleep hours. Furthermore, in this study the amount of caffeine consumption did have a significant correlation with EDS $(p<0.001)$. This result is in line with a previous study [17], however in the literature there are studies which are not consistent with our result [31,33]. In our study, it was found that more than $1 / 4$ (28.5\%) of all the participants suffered from sleepiness. Thus, the study demonstrates a clear association between the poor quality of life and daytime sleepiness in academic physicians ( $p<0.001)$. In a previous study, it has been reported that the quality of life decreased along with decreasing functional status [34].

One of the strengths of our study is the highest response rate of the few published studies targeting academic physicians. Another advantage is the fact that the ESS and 
the EQ-5D - the 2 well validated scales - were used in the study. Despite several important advantages of the present study, a relatively small sample size and nonresponse rate (36.4\%) are considered as its limitations.

\section{CONCLUSIONS}

In conclusion, we hope that this study will arouse or increase awareness of sleep deprivation among academic physicians. The relationship between sleep disorders and patients' safety remains to be explored. Further studies are needed to clarify this relationship.

\section{REFERENCES}

1. Chellappa SL, Araujo JF. Excessive daytime sleepiness in patients with depressive disorder. Rev Bras Psiquiatr. 2006;28: 126-9, http://dx.doi.org/10.1590/S1516-44462006000200010.

2. Santamaria J. How to evaluate excessive daytime sleepiness in Parkinson's disease. Neurology. 2004;63:21-3, http://dx. doi.org/10.1212/WNL.63.8_suppl_3.S21.

3. Luyster FS, Strollo PJ, Zee PC, Walsh JK. Sleep: A health imperative. Sleep. 2012;35(6):727-34, http://dx.doi.org/10.56 65/sleep.1846.

4. Kaneita Y, Ohida T. Association of current work and sleep situations with excessive daytime sleepiness and medical incidents among Japanese physicians. J Clin Sleep Med. 2011;7(5):512-22, http://dx.doi.org/10.5664/jcsm.1322.

5. Bahammam AS, Alaseem AM, Alzakri AA, Almeneessier AS, Sharif MM. The relationship between sleep and wake habits and academic performance in medical students: A cross-sectional study. BMC Med Educ. 2012;12(1):61, http://dx.doi.org/10.1186/1472-6920-12-61.

6. Dinges DF, Pack F, Williams K, Gillen KA, Powell JW, Ott GE, et al. Cumulative sleepiness, mood disturbance, and psychomotor vigilance performance decrements during a week of sleep restricted to 4-5 hours per night. Sleep. 1997;20:267-77.

7. Pilcher JJ, Huffcutt AI. Effects of sleep deprivation on performance: A meta-analysis. Sleep. 1996;19:318-26.
8. Van Dongen HP, Maislin G, Mullington JM, Dinges DF. The cumulative cost of additional wakefulness: Dose-response effects on neurobehavioral functions and sleep physiology from chronic sleep restriction and total sleep deprivation. Sleep. 2003;26:117-26.

9. Roehrs T, Carskadon MA, Dement WC, Roth T. Daytime sleepiness and alertness. In: Kryger MH, Roth T, Dement WC, editors. Principles and practice of sleep medicine. 4th ed. Philadelphia: W.B. Saunders Company; 2005. p. 39-50, http://dx.doi.org/10.1016/B0-72-1607977/50011-2.

10. Rosekind MR. Managing work schedules: An alertness and safety perspective. In: Kryger MH, Roth T, Dement WC, editors. Principles and practice of sleep medicine. 4th ed. Philadelphia: W.B. Saunders Company; 2005. p. 680-90, http://dx.doi.org/10.1016/B0-72-160797-7/50064-1.

11. Olson EJ, Drage LA, Auger RR. Sleep deprivation, physician performance, and patient safety. Chest. 2009;136: 1389-96, http://dx.doi.org/10.1378/chest.08-1952.

12. Hasler G, Buysse DJ, Gamma A, Ajdacic V, Eich D, Rössler W, et al. Excessive daytime sleepiness in young adults: A 20-year prospective community study. J Clin Psychiatry. 2005;66:521-9, http://dx.doi.org/10.4088/JCP.v66n0416.

13. Mota MC, De-Souza DA, Rossato LT, Silva CM, Araújo MB, Tufik S, et al. Dietary patterns, metabolic markers and subjective sleep measures in resident physicians. Chronobiol Int. 2013 Oct;30(8):1032-41, http://dx.doi.org/10.310 9/07420528.2013.796966.

14. Banerjee D, Vitiello MV, Grunstein RR. Pharmacotherapy for excessive daytime sleepiness. Sleep Med Rev. 2004;8: 339-54, http://dx.doi.org/10.1016/j.smrv.2004.03.002.

15. Bixler EO, Vgontzas AN, Lin HM, Calhoun SL, Vela-Bueno A, Kales A. Excessive daytime sleepiness in a general population sample: The role of sleep apnea, age, obesity, diabetes, and depression. J Clin Endocrinol Metab. 2005 Aug;90(8):4510-5, http://dx.doi.org/10.1210/jc.2005-0035.

16. Emmett BM, Dovey SM, Wheeler BJ. After-hours on-call: The effect on paediatricians' spouses and 
families. J Paediatr Child Health. 2013 Mar;49(3):246-50, http://dx.doi.org/10.1111/jpc.12108.

17. Roehrs T, Roth T. Caffeine: Sleep and daytime sleepiness. Sleep Med Rev. 2008 Apr;12(2):153-62, http://dx.doi. org/10.1016/j.smrv.2007.07.004.

18. Philibert I. Sleep loss and performance in residents and nonphysicians: A metaanalytic examination. Sleep. 2005;28(11):1392-402.

19. Surani S, Subramanian S, Aguillar R, Ahmed M, Varon J. Sleepiness in medical residents: Impact of mandated reduction in work hours. Sleep Med. 2007;8(1):90-3, http:/dx.doi. org/10.1016/j.sleep.2006.08.018.

20. Reddy R, Guntupalli K, Alapat P, Surani S, Casturi L, Subramanian S. Sleepiness in medical ICU residents. Chest. 2009;135(1):81-5, http://dx.doi.org/10.1378/chest.08-0821.

21. Izci B, Ardic S, Firat H, Sahin A, Altinors M, Karacan I. Reliability and validity studies of the Turkish version of the Epworth Sleepiness Scale. Sleep Breath. 2008;12:161-8, http:// dx.doi.org/10.1007/s11325-007-0145-7.

22. Johns MW. A new method for measuring daytime sleepiness: The Epworth sleepiness scale. Sleep. 1991;14:540-5.

23. Süt HK, Unsar S. Is EQ-5D a valid quality of life instrument in patients with acute coronary syndrome? Anadolu Kardiyol Derg. 2011;2:156-62.

24. Pallesen S, Nordhus IH, Omvik S, Sivertsen B, Tell GS, Bjorvatn B. Prevalence and risk factors of subjective sleepiness in the general adult population. Sleep. 2007;30:619-24.

25. Johns M, Hocking B. Daytime sleepiness and sleep habits of Australian workers. Sleep. 1997;20:844-9.
26. Melamed S, Oksenberg A. Excessive daytime sleepiness and risk of occupational injuries in non-shift daytime workers. Sleep. 2002;25:315-22.

27. Doi Y, Minowa M. Gender differences in excessive daytime sleepiness among Japanese workers. Soc Sci Med. 2003;56: 883-94, http://dx.doi.org/10.1016/S0277-9536(02)00089-8.

28. Drake CL, Roehrs T, Richardson G, Walsh JK, Roth T. Shift work sleep disorder: Prevalence and consequences beyond that of symptomatic day workers. Sleep. 2004;27:1453-62.

29. Garbarino S, de Carli F, Nobili L, Mascialino B, Squarcia S, Penco MA, et al. Sleepiness and sleep disorders in shift workers: A study on a group of Italian police officers. Sleep. 2002;25:648-53.

30. Chen I, Vorona R, Chiu R, Ware JC. A survey of subjective sleepiness and consequences in attending physicians. Behav Sleep Med. 2008;6(1):1-15, http://dx.doi. org/10.1080/15402000701796023.

31. Attarian H, Schuman C. Excessive daytime sleepiness among practicing physicians. J Clin Sleep Med. 2007;3(1):87.

32. Guilleminault C, Ramar K. Naps and drugs to combat fatigue and sleepiness. Ann Intern Med. 2006;144:856-7, http://dx.doi.org/10.7326/0003-4819-144-11-200606060-00012.

33. Katz ES, Maski K, Jenkins AJ. Drug testing in children with excessive daytime sleepiness during multiple sleep latency testing. J Clin Sleep Med. 2014 Aug 15;10(8):897-901, http:// dx.doi.org/10.5664/jcsm.3966.

34. Karapolat H, Durmaz B, Nalbantgil S, Durmaz I. [Quality of life and functional status in congestive heart failure]. Anadolu Kardiyol Derg. 2006;6:327-32. Turkish.

This work is available in Open Access model and licensed under a Creative Commons Attribution-NonCommercial 3.0 Poland License - http://creativecommons.org/ licenses/by-nc/3.0/pl/deed.en. 